\title{
De la self-hybridation aux cellules souches
}

\section{Orlan}

\section{(2) OpenEdition}

Journals

Édition électronique

URL : http://journals.openedition.org/actesbranly/451

DOI : $10.4000 /$ actesbranly.451

ISSN : 2105-2735

\section{Éditeur}

Musée du quai Branly Jacques Chirac

Référence électronique

Orlan, « De la self-hybridation aux cellules souches », Les actes de colloques du musée du quai Branly Jacques Chirac [En ligne], 2 | 2009, mis en ligne le 01 décembre 2009, consulté le 08 septembre 2020 URL : http://journals.openedition.org/actesbranly/451; DOI : https://doi.org/10.4000/actesbranly.451

Ce document a été généré automatiquement le 8 septembre 2020

(c) Tous droits réservés 


\section{De la self-hybridation aux cellules souches}

\section{Orlan}

1 Pendant des siècles, l'art occidental a été presqu'uniquement l'illustration et la propagande des croyances de la religion judéo-chrétienne. L'éducation chrétienne exerce à la fois le contrôle spirituel de la visagéité et de la paysagéité. Je n'ai pas eu d'instruction religieuse. Ma famille était libertaire anarchiste, espérantiste, nudiste et anticléricale. Mes premiers contacts avec la culture judéo-chrétienne furent en connexion avec mes premières approches artistiques, les images venues de l'histoire de l'art d'où je me suis mise à observer ce qui était dit et montré des femmes à d'autres époques. En même temps je pouvais observer dans mon époque ce qui était dit des femmes dans la publicité, les journaux et le cinéma et ce, avec des yeux critiques, avec les yeux rebelles de mon adolescence bien décidée à faire de l'art. Dès le début, mon œuvre a interrogé les pressions sociales, politiques, religieuses qui s'exercent sur les corps. J'ai pointé comment il a été fait violence aux corps et en particulier au corps des femmes. J'ai alors créé des séries d'œuvres à partir des images représentant vierges, madones et saintes. Ces images de femmes intégrées religieusement et montrées telles des modèles auxquelles je devais coller. Je les ai utilisées avec une distance critique. Tout en les investissant, en les enfilant comme on enfile les doigts dans un gant de marionnette, en leur faisant dire autre chose librement ou en grossissant les traits de leurs dires. En me les appropriant, et en essayant de les décoder, de démonter de l'image pour en refabriquer dans un cadre profane enfin en les utilisant pour ma propre construction intérieure et comme matériau pour construire mes œuvres.

2 Travailler sur le corps et sur son corps, c'est mettre ensemble l'intime et le social. Les luttes féministes ont porté au cœur des problèmes historiques l'évidence que le corps est politique. Mon travail se fait à partir des archives de notre patrimoine passant ainsi du religieux au culturel. J'ai toujours construit mes œuvres aux carrefours de deux histoires: mon histoire personnelle, mon roman personnel et une autre histoire, celle de l'art occidental ou non occidental. La première partie de mes oeuvres avant la transition de la série des opérations chirurgicales-performances cite et interroge cette 
culture qui m'a imprégnée mais que je connais peu et dont je me sens étrangère et/ou en opposition.

3 La deuxième partie postopératoire a été volontairement entreprise avec de nouveaux référents traités à partir de ma nouvelle figure obtenue dans mes performances.

Dans cette installation multimédia à l'intérieur de la chapelle baroque élevée à Sainte Orlan il y avait : des faux marbres et de vrais marbres, une vidéo, un hologramme, une sculpture me représentant en vierge blanche, des colombes vivantes et des colombes représentées en photo, des fleurs en plastique et de vrais lys dégageant leur parfum irreprésentable.

5 À l'intérieur donc le vrai et le faux, le vivant et l'artificiel se côtoyaient. Comme dans beaucoup de mes performances ou de mes photographies.

6 Le baiser de l'artiste : On pourrait dire une sculpture et sa performance entre «Bordel et Cathédrale ». Je peux dater ma vie comme ayant un avant et un après Le Baiser de l'Artiste. Car, il y a eu la rupture avec la famille, les voisins qui m'insultaient, la perte de mon emploi par un licenciement illicite, la perte de mon atelier, ce fut une période tragi-comique de mon existence. J'ai tout d'abord créé cette sculpture du baiser de l'artiste comme un arrangement avec des objets photographiques et des accessoires (lys en plastique, chaîne, cierges, textes...). Cette pièce illustrait un texte: "Face à une société de mères et de marchands ", qui commençait par les mots «au pied de la croix deux femmes, Marie et Marie Madeleine... » Deux stéréotypes d'image de la femme que j'ai beaucoup interrogés et auxquels on peut difficilement échapper. L'espace de cette performance était conçu comme un autel où étaient présenté "Sainte Orlan » et «Orlan-corps ».

7 Sur le même piédestal en bois peint en noir, d'un côté la représentation de Sainte Orlan à laquelle il était possible d'offrir un cierge pour $5 \mathrm{~F}$ et de l'autre la photo de mon torse collée sur bois et détourée qui devenait une sorte de distributeur automatique de baisers lorsque je m'installais derrière. Du côté d'Orlan-corps ma présence physique d'artiste à qui on pouvait acheter un baiser, pour $5 \mathrm{~F}$. Cette pièce était aussi faite pour créer des liens, et des questionnements sur le marché de l'art.

8 J'ai imposé cette performance à la Foire Internationale d'Art Contemporain à Paris au Grand Palais. Cette œuvre a été achetée par une institution publique française sans ma présence définitive sur l'autel. Elle est devenue un espace commémoratif sans culte mais sacré-sacralisé par l'institution - non pas l'institution religieuse, mais l'institution artistique qui l'a achetée et, à nouveau, par celle qui la montre.

9 On ne touche pas aux œuvres dans les musées, par contre on touche les images et les sculptures religieuses dans les églises. On leur parle, on les embrasse. Cette œuvre est donc devenue intouchable, inembrassable.

10 Avant cette œuvre, j'avais vendu au Portugal, à Caldas da Rainha, sur les marchés à côté des fruits et légumes, mon corps en morceaux : on pouvait acheter mon œil, mon sein, mon pied, mon visage, mon sexe etc. en: photo détourée et collée sur bois, des fragments de mon corps tels des ex-voto profanes, comme des blasons anatomiques.

11 Régis Debray écrit «Le divin, objecte l'iconoclaste, est indescriptible, c'est pourquoi toute image de lui ne peut-être que 'pseudo' et non 'homo', mensongère et non ressemblante. Spirituel et invisible seraient alors synonymes. C'est ce couple immémorial que brise le christianisme, révolution dans la Révélation ». 

idolâtre celui qui vénère les icônes du Christ, de la Vierge, des anges et des saints, parce que "l'hommage rendu à l'icône va au prototype ", mais que refuser cet hommage « reviendrait à nier l'Incarnation du Verbe de Dieu».

13 Je ne me prends pas pour une déesse mais: je me sens moi-même irreprésentable, infigurable. Toute image de moi-même est pseudo, qu'elle soit présence charnelle ou verbale.

Toute représentation est insuffisante, mais ne pas en produire serait pire. Ce serait être sans figure, sans image, sans représentation, et ce n'est pas le visage ni la visagéité, ni la dévisagéité qui me sauvent. Pour moi, ce qui compte c'est tourner autour de ces images possibles, les faire sortir, les pousser à sortir, à tâtons, toujours étonnée de la vision de ce qui pourrait être soi-même et de cette matière d'être. Et ce quelle que soit l'image, ces images sont toujours d'une inquiétante étrangeté.

$$
\text { vierges et des saints - iconographie qui permet de tourner autour, d'approcher quelque }
$$
chose, de se donner à voir quelque chose plutôt que rien.

Se donner à voir, être vue, faire croire que l'on peut être vue avec des images successives, des images de paille, des pseudo, tout au long de mon œuvre est une kyrielle d'images de moi, une myriade de photos, un flux, une explosion, une hémorragie, un charnier telle la photo, une dysenterie d'images, tel Adam né de la fange et de la boue telle Lilith.

17 Tels comme autant de commencement de preuves de mon incarnation née dans cette fange que je préfèrerais nommer notre "soupe primordiale ».

18 J'apparais en vierge blanche, ou en vierge noire dans cette série des photographies faite en studio intitulée Skaï and Sky et Vidéo, dans une série importante intitulée «Etude documentaire : Le drapé - le baroque » que j'ai conduite pendant une dizaine d'années.

19 Elle désigne l'ancien et l'actuel dans un même espace, d'où je manipulais deux croix, une noire et une blanche, comme des objets qui n'ont pas d'importance religieuse particulière pour moi. Ce n'était pas transgressif car c'était seulement pour moi deux morceaux de bois entourés d'une multitude de perles blanches ou noires.

20 Mon attitude est la même avec les autres cultures que j'interroge. Mes poses en faisaient parfois des objets apotropaïques ou bien je les manipulais de manière légère, faussement naïve, car j'étais consciente à la fois des images qu'elles produisent, et du type d'images qu'elles questionnent par conséquent de la valeur symbolique à laquelle on les associe. Au fur et à mesure de cette série s'est construit le personnage de Sainte Orlan fiction d'un personnage religieux se glissant dans son stéréotype. La photo transforme notre corps-présence en image. La photo un début de preuve de ma présence physique sur terre bien qu'il puisse toujours y avoir le soupçon de sa fabrication par ordinateur. L'image de la sainte, de la vierge, garde son aura, elle tient en respect le spectateur.

21 Lorsque j'ai crée le baiser de l'artiste, on m'appelait «miss", tout juste si l'on me pinçait pas les fesses, je n'étais qu'une femme en cheveux, je perdais le statut d'artiste, je perdais mon aura. 

mes œuvres. Le bloc opératoire, c'est un atelier d'artiste, dans lequel j'avais conscience de produire des dessins faits avec mes doigts et mon sang, des images vidéographiques, des vidéos, des films, des images photographiques, des reliquaires, des dessins etc. C'est aussi un espace de performance retransmis par satellite dans plusieurs points du monde dont le Centre Georges Pompidou, le Centre McLuhan à Toronto,...

27 C'est à la lecture d'un texte, d'Eugénie Lemoine Luccioni psychanalyste lacanien que l'idée de ce passage à l'acte m'a traversé (de la lecture au passage à l'acte). En exergue à toutes mes opérations chirurgicales-performances: je lisais donc cet extrait de son livre La robe qui dit en résumant ceci :

La peau est décevante ... dans la vie, on a que sa peau... Il y a maldonne dans les rapports humains parce que l'on n'est jamais ce que l'on a... J'ai une peau d'ange mais je suis un chacal... Une peau de crocodile mais je suis un toutou, une peau de noire mais je suis un blanc une peau de femme mais je suis un homme; je n'ai jamais la peau de ce que je suis. Il 
n'y a pas d'exception à la règle parce que je ne suis

jamais ce que j'ai.

28 A la lecture de ce texte, j'ai pensé qu'à notre époque nous commencions à avoir les moyens de réduire cet écart; en particulier à l'aide de la chirurgie. Qu'il devenait donc possible de ramener l'image interne à l'image externe et de s'approprier son incarnation, dans l'idée de la sculpture de soi, de l'invention de soi. Cette performance est comme l'accouchement de soi m'aime, elle est en rupture avec la filiation, l'image de la mère et le nom du père. «Orlan accouche d'elle-m'aime » est le titre d'une de mes premières œuvres photographiques.

29 En français, "elle-m'aime » est un jeu de mots où m'aime indique le verbe aimer conjugué au singulier au lieu du mot même qui à la même sonorité mais qui veut dire identique.

30 Les opérations chirurgicales ont été pratiquées de 1990 à 1993. La septième opérationperformance réalisée à New York le 21 novembre 1993 était basée sur un concept : L'Omniprésence. Elle a en fait été diffusée en direct par satellite dans ma galerie, la galerie Sandra Gering à New York, au Centre Georges Pompidou, au Centre Mac-Luhan à Toronto, au Centre multimédia de Banff et dans une dizaine d'autres lieux où nous étions en contact par des moyens de transmissions interactifs.

Chaque opération-chirurgicale performance a été construite sur un texte philosophique ou psychanalytique, ou littéraire: Eugénie Lemoine Luccioni, Michel Serres, textes hindous sanscrits, Alphonse Allais, Antonin Artaud, Élisabeth Betuel Fiebig, Raphael Cuir, Julia

Kristeva, etc. Je lisais des textes le plus longtemps possible pendant l'opération, même lorsque l'on m'opérait le visage. Ce qui donnait dans les dernières opérations l'image d'un cadavre autopsié dont la parole continuait encore, comme détachée du corps.

C'est un moment de passage entre deux images, entre deux états, mis en scène avec les "objets du culte», les outils de ce passage, de ce rituel sont: livres, bistouris, encarteuse, scialytique, caméra, costumes, champ opératoire, vidéo, photo, décor, affiches de cinéma peintes, performances, lectures...

Mes œuvres se sont mêlées à mon existence. À chaque œuvre, c'est refaire une entrée, son entrée, se ré-envisager en utilisant la vie comme un phénomène esthétique récupérable, c'est aussi créer des moments d'intensités pour soi-même et autrui.

Se mettre hors de soi pour devenir soi. Cette série de performance a été créée pour mettre de la figure sur mon visage. Un travail entre figuration, défiguration et réfiguration dans un corps tantôt sujet tantôt objet, tantôt avoir un corps, tantôt être ce corps, et jouant entre ma présence et ma représentation jusqu'à tenter de se désinscrire de la tradition et en même temps tenter de se désinscrire pour s'inscrire en creux, en faux, dans une société qui nous désigne les modèles à intégrer, que ce soient ceux de l'histoire de l'art ou ceux des magazines ou de la pub, la femme qu'il faut être, l'art qu'il faut faire et ce qu'il faut penser.

36 Ce n'était bien sûr qu'une tentative de dé-formatage : il est difficile de produire des images en dehors. Il est possible au moins de donner des images répliques. Qui font réponses qui s'installent dans l'autre plateau de la balance des données et qui instaure un débat dont un débat féministe.

37 J'ai choisi d'utiliser la littéralité de la performance pour parler de la violence faite au corps, plus particulièrement au corps des femmes. La religion chrétienne a rejeté le 
corps, et particulièrement le corps-plaisir. Lorsqu'elle s'en occupe c'est pour le supplicier, le couper, le faire saigner. Elle propose un corps-coupable, un corpssouffrance, un corps qui doit souffrir. Mon premier deal avec le chirurgien: était pas de douleur ni pendant ni après.

A ce je vais vous lire quelques extraits du manifeste que j'ai écrit au moment de faire ces opérations chirurgicales. Je l'ai nommé «l'art charnel »et je l'ai écrit avant les opérations :

Définition : L'Art Charnel est un travail d'autoportrait au sens classique, mais avec des moyens technologiques qui sont ceux de son temps. Il oscille entre défiguration et refiguration. Il s'inscrit dans la chair parce que notre époque commence à en donner la possibilité. Le corps devient un « ready-made modifié » car il n'est plus ce ready-made idéal qu'il suffit de signer.

Distinction : Contrairement au «Body Art» dont il se distingue, l'Art Charnel ne désire pas la douleur, ne la recherche pas comme source de purification, ne la conçoit pas comme Rédemption. L'Art Charnel ne s'intéresse pas au résultat plastique final, mais à l'opération chirurgicale-performance et au corps modifié, devenu lieu de débat public.

Athéisme : En clair, l'Art Charnel n'est pas l'héritier de la tradition chrétienne, contre laquelle il lutte! Il pointe sa négation du «corps-plaisir » et met à nu ses lieux d'effondrement face à la découverte scientifique. L'Art Charnel n'est pas davantage l'héritier d'une hagiographie traversée de décollations et autres martyres, il ajoute plutôt qu'il n'enlève, augmente les facultés au lieu de les réduire, l'Art Charnel ne se veut pas automutilant. L'Art Charnel transforme le corps en langue et renverse le principe chrétien du verbe qui se fait chair au profit de la chair faite verbe ; seule la voix d'Orlan restera inchangée, l'artiste travaille sur la représentation. L'Art Charnel juge anachronique et ridicule le fameux «tu accoucheras dans la douleur ", comme Artaud il veut en finir avec le jugement de Dieu ; désormais nous avons la péridurale et de multiples anesthésiants ainsi que les analgésiques, vive la morphine! A bas la douleur !

Perception : Désormais je peux voir mon propre corps ouvert sans en souffrir ...Je peux me voir jusqu'au fond des entrailles, nouveau stade du miroir. «Je peux voir le cœur de mon amant et son dessin splendide n'a rien à voir avec les mièvreries symboliques habituellement dessinées ». - Chérie, j'aime ta rate, j'aime ton foie, j'adore ton pancréas et la ligne de ton fémur m'excite.

Liberté : L'Art Charnel affirme la liberté individuelle de l'artiste et en ce sens il lutte aussi contre les aprioris, les diktats ; c'est pourquoi il s'inscrit dans le social, dans les média (où il fait scandale parce qu'il bouscule les idées reçues) et ira jusqu'au judiciaire.

Mise au point : L'Art Charnel n'est pas contre la chirurgie esthétique, mais contre les standards qu'elle véhicule et qui s'inscrivent particulièrement dans les chairs féminines, mais aussi masculines. L'Art Charnel est féministe, c'est nécessaire. L'Art Charnel s'intéresse à la chirurgie esthétique, mais aussi aux techniques de pointe de la médecine et de la biologie qui mettent en question le statut du corps et posent des problèmes éthiques.

Style : L'Art Charnel aime le baroque et la parodie, le grotesque et les styles laisséspour-compte, car l'Art Charnel s'oppose aux pressions sociales qui s'exercent tant sur le corps humain que sur le corps des œuvres d'art.

J'ai changé de visage, j'ai vendu mes baisers d'artiste et je vends ma chair sans que le ciel me soit tombé sur la tête. J'ai agi sans avoir peur, en ne me sentant aucunement influencée ou menacée par la peur collective et ancestrale de toucher à l'intégrité du corps. Ce sentiment anachronique né de l'idée que le corps est sacré et intouchable, intransformable. Un sentiment qui persiste alors que de nombreux corps ont été et sont continuellement transformés: visages refaits, rotules, hanches changées, dents 
remplacées, greffes d'organes... sans problèmes tant physiques, que psychologique. Une opération chirurgicale esthétique ou pas est toujours contre nature de même que prendre des antibiotiques pour ne pas mourir d'une infection n'est pas naturel. L'anatomie n'est plus le destin mais un accessoire volontaire de la présence. Nous ne pouvons plus perdre la face, être défigurés puisque la greffe d'un visage vient d'être faite avec succès. La présence c'est déjà la pornographie, le corps contient la virtualité de sa manifestation. Mon œuvre n'est pas un travail iconoclaste c'est une ouverture sur toutes les images possibles fortifiant les identités mouvantes, mutantes nomades

Voici maintenant quatre œuvres d'un autre type: de reliques en reliquaires. La première est un dessin fait avec mes doigts et mon sang pendant le geste opératoire. La deuxième une gaze médicale avec mon sang séché sur laquelle j'ai fait un transfert photographique de mon visage. La quatrième est un petit reliquaire avec ma chair et de la lumière Et la dernière, un reliquaire intitulé « My flesh the text and the languages ». L'idée de cette série est de produire le plus de reliquaires possible, fabriqués en verre de banque anti-effraction avec un cadre en métal soudé dans un sentiment d'inviolabilité de $1,10 \mathrm{~m} . \times 0,75 \mathrm{~m} \times 0,15 \mathrm{~m}$ se présentant toujours de la même manière et toujours avec le même texte mais chaque fois dans une traduction différente jusqu'à épuisement $\mathrm{du}$ corps et de la matière chair à reliquaire récupérée pendant les opérations; chaque fois dans une langue différente jusqu'à ce que je n'ai plus de chair à incruster dans le centre du reliquaire... Mettant ainsi en évidence un rapport entre la chair et le verbe... Le verbe cause efficace de l'incarnation.

Le monstre courant tatoué, ambidextre, hermaphrodite et métis, que pourrait-il nous faire voir, à présent, sous sa peau ? Oui le sang et la chair. La science parle des organes, de fonctions, de cellules et de molécules, pour avouer enfin qu'il y a beau temps que l'on ne parle plus de vie dans les laboratoires, mais elle ne dit jamais la chair, qui, tout justement, désigne le mélange, en un lieu donné du corps, ici et maintenant de muscles et de sang, de peau et de poils, d'os, de nerfs, et de fonctions diverses, qui mêle donc ce que le savoir pertinent analyse.

42 Platon séparait le corps et l'esprit. Les idées sont supérieures à tout, dès qu'on est dans la chair, on se dégrade. J'ai voulu faire une œuvre, un art qui puiserait dans le conceptuel mais qui serait charnel, non seulement par la couleur et la forme, mais dans la chair et par la chair et qui se permettrait la présence même de l'artiste dans l'œuvre.

Le concept étant le squelette, et la chair est la qualité de la matérialité qui nous révèle le sens de l'idée un corps devenant langage et retournant le principe chrétien du verbe fait chair au profit de la chair faite verbe. Dans cette série de reliquaires, le corps et la chair sont là, prêts à être vendus comme oeuvre d'art dépassant le tabou de la vente de son corps.

Le texte d'origine est en français, les traductions nous parlent d'un texte dont la traduction est sa représentation, le corps du texte, le corps des lettres, la chair est là pouvant se donner à l'analyse ADN, prenant le risque d'être utilisé plus tard. Et qu'un corps, qu'un répliquant, qu'un clone soit fabriqué. Ne sommes-nous pas à l'ère de la reproductivité des images? et très bientôt à l'ère de la reproductivité de la chair et de l'être humain à son image ou peut-être sans son image dans une autre sorte d'apparence.

Ce reliquaire un jour sera vieux: et appartiendra au passé et il pourra à son tour devenir un jouet, une reprise, une autre représentation. «Focillon comparait l'artiste à un 
Centaure. On peut dire aussi à un médiateur indécis, oscillant entre un devenir - Verbe et un devenir - Chair ». Devant ce reliquaire l'historien de l'art sera comme l'historien dont parlait Walter Benjamin, « un enfant qui joue avec les lambeaux du temps » et les scientifiques joueront peut-être avec les lambeaux de ma chair, avec mes gênes. Le travail post chirurgical remet en cause les standards de beauté et le statut du corps dans la culture occidentale, en mettant en perspective les iconographies d'origines non-occidentales. Les opérations chirurgicales performances sont à la charnière toutes mes citations et interrogations de l'art occidental se sont arrêtées à ces performances et ensuite j'ai fait références qu'aux œuvres non occidentales. Chaque « civilisation » a voulu fabriquer les corps. Mon travail va et vient entre la chair et ce que l'on nomme couramment le virtuel, entre la littéralité de la performance et la photographie digitale.

Comme vous pouvez le voir, j'ai hybridé une photo d'une statue olmèque avec une photo de mon visage. J'ai gardé l'apparence de la terre et de la pierre car le référent est la statuaire. Celle-ci est maya [2] et celle-là est à partir du masque funéraire du Roi Pacal [3]. Les déformations du crâne m'ont beaucoup intéressée. Ce désir de transformer le crâne, de le façonner, le reconstruire se retrouve dans de nombreuses cultures, précolombiennes, africaines, égyptiennes, mérovingiennes... La déformation du crâne est assez facile à obtenir. Il suffit de placer des morceaux de bois, et/ou des bandages sur la tête d'un bébé et lorsque la fontanelle est solide le crane à pris une autre forme que celle prévue par la nature.

Il y a quelques générations, dans le Sud-Ouest de la France, dans la région d'Albi, ce genre de pratique était encore courant. Le strabisme était aussi créé en plaçant une boule d'argile ou un coquillage en haut du nez, entre les yeux des bébés. Cette transformation alors considérée comme belle, remet en question les standards actuels de beauté, car nous détestons le strabisme et essayons de le corriger.

Cette série de self-hybridation africaine fait référence à l'histoire de l'ethnographie occidentale. Cet exemple est basé sur une photographie noir et blanc d'une femme nedebele. Toute la série africaine est en noir et blanc, même si j'utilise un masque ou de la statuaire.

Ces photos de 1,24 x 1,55 sont présentées collées sous plexiglas. Le titre est important dans cette série. Mon origine est énoncée parallèlement à l'origine de la source : Femme Surmas avec labrets et visage de femme Euro- Stephanoise avec bigoudis. Je suis née à Saint-Étienne, vive le Pilat et le Forez libre !

Depuis mon séjour au Getty Research Institute aux Etats-Unis, je travaille sur une autre série au croisement de l'histoire de l'Amérique et de l'histoire de l'Art. Ces images sont conçues d'après le travail d'un peintre américain du 19e siècle, George Catlin. Avant l'invention de la photographie, il a peint un grand nombre de chefs de tribu indiens et leurs épouses. Élaborant ainsi un travail d'archivage dans les années 1830. J'ai pris la même pose que celle des portraits de Catlin, et j'ai essayé d'avoir le même regard, puis j'ai hybridé les deux photos, gardant la texture de la peinture.

51 La première série d'hybridation, la précolombienne, est aussi une hybridation entre la photographie digitale et la sculpture, la série africaine, entre les débuts de la photographie et les nouvelles technologies de l'image. Pour ces séries, j'ai utilisé un logiciel de graphisme très spécialisé. La dernière série, hybride peinture et photographie digitale. C'est très important pour moi puisque toute ma vie j'ai essayé de 
casser les barrières, les murs entre les générations, les sexes, les cultures et les pratiques artistiques.

Pour finir parle d'une autre installation qui s'appelle "Le manteau d'Arlequin », une grande projection vidéo de cellules humaine et animale et dans cette projection il y a un bio-réacteur. La figure d'Arlequin, dans le motif du manteau, représente une figure de l'hybridation. L'idée est de présenter la réalisation d'un manteau composite, organique, fait de l'assemblage. Le philosophe français Michel Serres a écrit Laïcité en préface de son livre Le "tiers-instruit". J'ai utilisé ce texte pour construire et développer aussi ma performance intitulée « Image, nouvelle image(s) ». Michel Serres utilise la figure de l'Arlequin comme métaphore du croisement, de l'acceptation de l'autre, de la conjonction et intersection. Après biopsie, mes cellules ont été cultivées à l'UWA School of Anatomy and Human Biology Laboratories sous la direction de Symbiotica, laboratoire artistique dédié à la recherche, apprentissage et critique des sciences de la vie.

Et donc je reviens au manteau. Pour moi c'est très difficile de se battre avec ce qui n'est pas visible à l'œil nu puisqu'on doit faire une image, représenter quelque chose : il doit $\mathrm{y}$ avoir quelque chose à voir. Et en fait à l'intérieur de ce bioréacteur il y a de l'oxygène, etc., qui permet la vie des cellules. Il y a non seulement mes cellules de peau mais aussi des cellules d'origine différente. Ces cellules ont été différentes dans chaque exposition. Il y a aussi des cellules venant d'espèces différentes. Bien évidemment il ne s'agit pas d'hybridation. C'est symboliquement dans ce sens, mais c'est plutôt l'idée d'une coexistence car pour le moment on est en train de chercher la solution pour hybrider mais actuellement les cellules se repoussent les unes les autres. Donc en fait j'ai pris la préface du "tiers-instruit" de Michel Serres, j'ai travaillé plusieurs fois avec ce texte pour faire des choses très différentes d'ailleurs. Et en fait Michel Serres utilise la figure de l'Arlequin comme métaphore du croisement, de la captation de l'autre, de la différence, de l'autre, de la conjonction et de l'intersection.

Symbiotica est le premier laboratoire de recherche de ce type, en ce qu'il permet aux artistes de pratiquer des manipulations et des recherches en biologie, dans un département universitaire de sciences. Les cultures de tissus ont été présentées in vivo durant les différentes étapes de l'élaboration du manteau, et finalement conservées et teintées après leur développement dans des boîtes de pétri. Donc des cellules vivantes présentées dans un incubateur, des cellules mortes dans des pétris et des projections de vidéos représentant des cellules vivantes. Ces cultures posent différentes questions de natures techniques et éthiques et l'installation parle de la fragilité du vivant et de la difficulté pour un artiste plasticien de travailler avec, puisque les cellules sont invisibles à l'œil nu et aussi très difficiles à maintenir en vie.

Ce projet suit mon travail sur l'hybridation utilisant la photographie digitale. Mes dernières séries "Selfhybridation Précolombienne ", "Self-hybridation Africaine " et "Self-hybridation Indiens d'Amérique » mettent en perspective les canons de beauté d'autres cultures et médias (sculpture, photo, peinture) avec ma propre image sensée représenter ces standards de beauté de ma propre culture, tout en respectant la différence de l'un et l'autre.

Cette installation questionne la relation actuellement établie entre la (bio)technologie et la culture artistique. Mon œuvre en général parle de frontières et des endroits où se rejoignent l'anthropologie et l'art mais aussi les catégories, les formatages et les croyances que ce soient celles de ma culture et celles des autres cultures. 


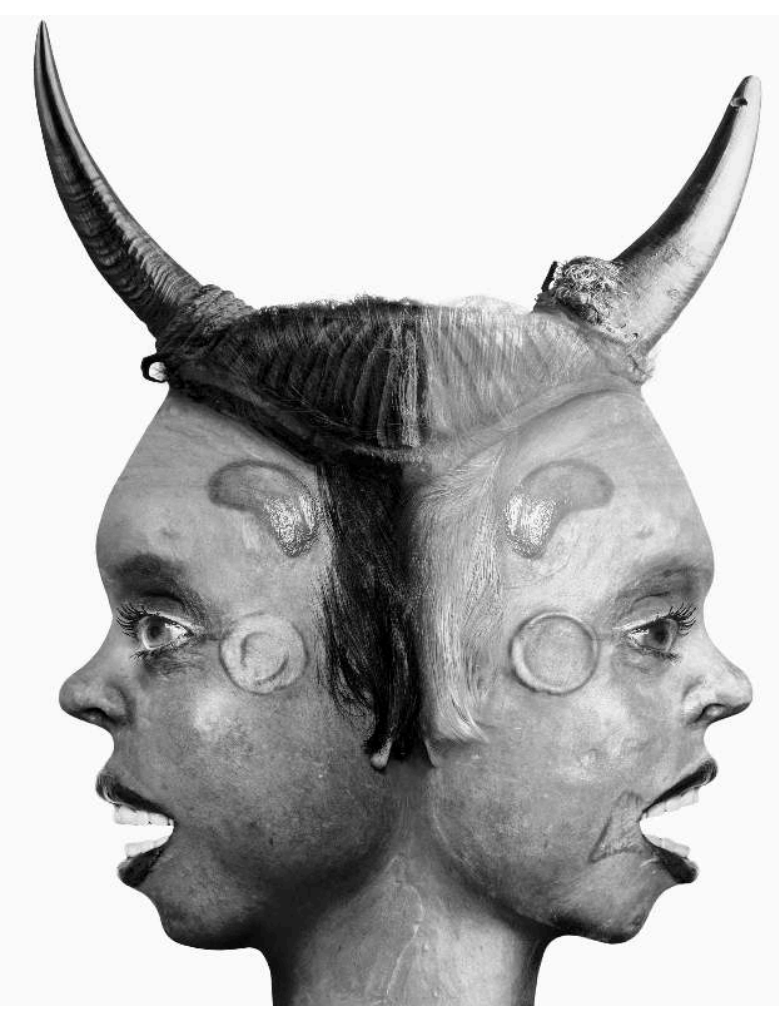

Courtesy galerie Micel Rein, Paris

\section{RÉSUMÉS}

Le parcours artistique d'Orlan l'a amené à croiser des thèmes de prédilection des anthropologues. A partir de ses travaux sur l'hagiographie (Sainte Orlan), sur la self-hybridation (précolombienne, africaine...), mais aussi à partir de son travail sur l'hybridation des cellules souches, elle montre dans quelle mesure elle prend en considération et dialogue - ou s'oppose - avec les cultures dont elle s'inspire.

Orlan's artistic journey has led her to touch on several of the topics most often examined in anthropology. From her work on hagiography ('Saint Orlan') and on self-hybridization (PreColombian, African...), as well as with her work on the hybridization of stem cells, her oeuvre shows to what extent she thinks about and dialogues - or disagrees - with the cultures that inspire her. 


\section{AUTEUR}

\section{ORLAN}

Depuis 1964, ORLAN pratique la peinture, la sculpture, la poésie, la danse, le théâtre et la performance. Elle réalise ses premières œuvres photographiques en considérant son propre corps comme une sculpture. Très tôt, elle en fait le sujet d'un débat public, réalisant parfois des performances provocantes dans les institutions les plus prestigieuses. Explorant des voies multiples et utilisant toutes sortes de supports, de la performance à la vidéo, de la photographie aux installations, l'œuvre d'ORLAN se révèle complexe et s'articule autour de thèmes récurrents : problématiques du corps et de la sexualité, questions sur l'identité de la femme, dialogue entre le virtuel et le réel, défiguration et refiguration. 